\title{
Quality Control of Jati Belanda Leaves (Guazuma ulmifolia) using Image Analysis and Chemometrics
}

Penulis

Afiliasi

\section{Rudi Heryanto $^{1,2^{*}}$, Yeni Herdiyeni ${ }^{1,3}$, Yuthika Rizqi Noviyanti ${ }^{2}$}

${ }^{1}$ Biopharmaca Research Center, Bogor Agricultural University, Indonesia

${ }^{2}$ Department of Chemistry, Bogor Agricultural University, Indonesia

${ }^{3}$ Department of Computer Sciences, Bogor Agricultural University, Indonesia

\section{Kata Kunci \\ - Quality Control \\ - Guazuma ulmifolia \\ - Image analysis \\ $\rightarrow$ Chemometrics}

Diterima 5 Mei 2015

Direvisi 2 September 2015

Disetujui 7 Januari 2016

*Penulis korespondensi Rudi Heryanto

Biopharmaca Research Center Jl. Taman Kencana No. 3 Bogor, Indonesia 16128 Tel. +62-251 8373561

rudi_heryanto@apps.ipb.ac.id

\section{Abstract}

The quality of medicinal plants, such as Guazuma ulmifolia (jati belanda, JB), affects the quality of the herbal material derived from them, and can be determined using image analysis. The objective of this study is to investigate the possibility of using an image-generated spectrum and chemometrics as a method for quality control of Jati belanda leaves. Three different quality levels of JB leaves were determined, based on their harvesting time, and confirmed by total flavonoid content analysis. The images of JB samples were collected and reconstructed as a reflection spectrum using the Wiener estimation. The reconstructed spectrum had a goodness-of-fit coefficient of 0.9576 and a root-mean-square-error (RMSE) of $36.65 \%$, compared to the experimental spectrum. Principal Component Analysis (PCA) was used to classify the JB reconstructed spectrum based on its quality. A score plot of two PCs that represented $98 \%$ variance was able to group the JB spectrum. Further analysis using Partial Least Squares-Discriminant Analysis (PLSDA) showed that the method can result in around $90 \%$ prediction success rate with external validation. This study indicates that image analysis and chemometrics could be used as quality control methods for herbal material.

\section{Introduction}

The content of the active compounds of medicinal plants varies widely, depending on the species, varieties, geographical origin, cultivation, harvesting methods, and post-harvest processing (Singh et al. 2010). In addition, the age of plants can be an indicator of medicinal plant quality (Anuradha et al. 2010). These variations can cause inconsistencies in herbal product stability and safety. Furthermore, the increasing use of herbal products, without any backup from scientific knowledge, may lead to such use causing harm. Therefore, maintaining consistency in the efficacy of herbal medicine is very important, and can be 
achieved through the use of effective quality control methods.

The Quality control of medicinal plants can be carried out using a multi-component approach or fingerprint analysis. Many chromatographic fingerprints are used for this purpose, such as thinlayer chromatography (TLC), gas chromatography (GC), high performance liquid chromatography (HPLC), and capillary electrophoresis (Borges et al. 2007). The fingerprint from FTIR, combined with chemometrics analysis, has also been used for herbal quality control. There is also a research paper that detailed the use of fingerprint analysis from a portable photometer for quality control of Guazuma ulmifolia leaves (Kurniawan 2012). As an alternative, image processing techniques have the potential to be developed as quality control methods for medicinal plants.

There are two image processing methods, namely chemical imaging and spectral imaging. Chemical imaging is a technique that combines conventional imaging and spectroscopy to provide spatial and spectral information on an object. This technique has been used in the pharmaceutical industry as a quality control method in various stages of the drug production process. Chemical imaging is an analytical method that has high selectivity, specificity, and is non-destructive to a sample. But it requires costly instrumentation and needs a special filter for operation (Gowen et al. 2008). Another method, spectral imaging, has been used by Shatilova (2008) to estimate the content of carotenoids in the skin of the Arctic charr fish (Salvelinus alpinus). The estimation was carried out by means of spectral reflectance reconstructed from digital images.

In term of practicality, a spectral imaging method has advantages, because it can use a commercial digital camera as an instrument for image retrieval. In this study, we used spectral imaging as a quality control method for medicinal plant material of jati belanda (Guazuma ulmifolia Lamk.). The quality of jati belanda was differentiated based on the different ages at harvesting time, as indicated by the flavonoid contents (Febrandy 2006). Samples of jati belanda leaves were photographed using a digital camera with a calibrated image capture system. The digital image is representative of the interaction resulting from the absorptionreflection of visible radiation with the chemical compounds in the sample. Information on this interaction is contained in the RGB values of the image. Thus the spectral image acquired chemical information from the sample from its spectral reflectance. The discrimination of jati belanda sample quality using its converted spectral reflectance was carried out by using pattern recognition techniques, i.e. PCA and PLSDA.

The diversity of jati belanda quality comes from the different ages of the plants, and it was correlated with different leaf color intensity. Then the sample quality was represented by constructed reflectance spectra evaluated by using pattern recognition techniques (PCA and PLSDA).

\section{Materials and Methods}

\section{Materials}

The materials used in this study were jati belanda leaves (aged 1, 2, and 3 months), which were taken from the Biopharmaca Research Center Station, Dramaga, Bogor. Other material used were 23 different types of medicinal plants leaves, 70\% ethanol, hexamethylentetramine $0.5 \% \mathrm{w} / \mathrm{v}$, acetone, $\mathrm{HCl} 25 \%$ in water, ethyl acetate, glacial acetic acid $5 \%$ $\mathrm{v} / \mathrm{v}$ (in methanol), $\mathrm{AlCl}_{3} 2 \%$ in water, quercetin, and methanol. The main instruments used were a UV-Vis spectrophotometer Shimadzu 1700 PC, a USB 2000 spectrometer, a sonicator, a rotary evaporator, an analytical balance, and a Canon $8 \mathrm{MP}$ digital camera. The software used was The Unscrambler 10.2, Matlab, and SPSS version 16.

\section{Methods}

Jati belanda leaves samples with different quality levels (1, 2, and 3 months) were harvested from the Biopharmaca field station, Dramaga. The images of the leaves were taken by a Canon $8 \mathrm{MP}$ digital camera. Using the Wiener estimation, the images were converted to their reflectance spectra. At the same time, the flavonoid content of the leaves was also determined, for use as a quality indicator. Finally, the correlation between spectra 
and quality properties was evaluated using chemometric techniques (PCA \& PLSDA).

\section{Image Acquisition (Orava et al. 2012)}

In this research, two groups of images were collected from several samples. The first group was used as training data for generating an estimator matrix (W) using the Wiener estimation. The images were taken from 97 standards color plates in the visible range and 23 different types of medicinal plant. The second group was used as testing data for checking the quality of spectra reflectance constructed from Wiener estimation. As many as 30 Jati belanda leaves were used as samples.

Images of both groups were captured using a Canon 8 MP digital camera. All the samples were placed inside an enclosed space with a white background. The images were shot at an angle perpendicular to the samples within a $50 \mathrm{~cm}$ distance. To provide sufficient illumination, a tungsten lamp was used at a distance of $30 \mathrm{~cm}$ from the leaves while taking the images. All the settings used in image acquisition were set to manual mode and constantly maintained. All samples were also subjected to reflectance spectra measurement using an Oceanoptics USB2000 spectrophotometer. These spectra were used as reference spectra.

\section{Spectral Reflectance Reconstruction (Shatilova 2008)}

Reconstruction of the spectral reflectance of an image was carried out using the Wiener estimation technique. To reconstruct spectral reflectance from the sample image, a training data matrix $W$ obtained from the Wiener estimation technique was required. This computational process was calculated using MATLAB 7.7.0 (R2008b). The Wiener estimation technique for the image can be defined in equation (1):

$$
\text { Yo }=X . W
$$

$X$ was the matrix form of the RGB value of the image from the first group. Yo was the reflectance spectra matrix of the training group, obtained from measurements from a USB 2000 spectrophotometer. The data consisted of many samples (I) and many channel spectra ( $n$ ). W was a transformation matrix. The matrix $W$ was estimated explicitly by the formula

$$
W=R_{r v} R^{-1}
$$

Table 1. Three types of polynomial models were used for the reconstruction of the spectra

\begin{tabular}{cc}
\hline Terms & Polynomial \\
\hline 3 & 1st order \\
& R G B \\
7 & 2nd order \\
& $R$ B R $^{2} \mathrm{G}^{2} \mathrm{~B}^{2} \mathrm{RGB}$ \\
10 & 3 rd order \\
\hline
\end{tabular}

Rrv and Rvv were the correlation matrices. Rrv and Rvv matrices can be defined by the formula:

$$
\operatorname{Rrv}=\left\langle\mathrm{rv}^{\mathrm{t}}\right\rangle, \mathrm{Rvv}=\left\langle\mathrm{vv} v^{\mathrm{t}}\right\rangle
$$

where $r$ was a column vector with $k$ elements as representative value of the reflectance spectrum of 1 pixel in the image and $v$ is a column vector with $m$ elements (RGB). In this model, the unknown coefficients can be calculated by using the quadratic approach based on the pseudo-inverse method. In estimating $W$, the $v$ matrix can consist of first order $R G B$ values. If they are not giving good estimations, first-order linear equations could be upgraded to a higher order polynomial by adding and combining the product (RGB). Polynomial terms used in this study can be seen in Table 1.

The error measurement and similarity values of the reconstructed reflectance spectra of the images from the original reflectance spectra were determined by using the root-mean-square-error (RMSE) and the goodness-of-fit coefficient (GFC). RMSE calculation was calculated by the formula:

$$
\text { RMSE }=\left(\frac{\sum_{i=1}^{n}(s(i)-\tilde{s}(i))^{2}}{n}\right)^{1 / 2}
$$

$\mathrm{s}$ was the original value of the reflectance spectra of 10 leaves of jati belanda, $\widetilde{s}$ was the reconstructed value of reflectance spectra from 10 leaves of jati belanda, and $\mathrm{n}$ is the number of spectral reflectance channels. 


$$
G F C=\frac{\left|\sum_{j} R_{m}\left(\lambda_{j}\right) R_{r}\left(\lambda_{j}\right)\right|}{\left[\left|\sum_{j}\left[R_{m}\left(\lambda_{j}\right)\right]^{2}\right|\right]^{1 / 2}\left[\Sigma_{j}\left[R_{r}\left(\lambda_{j}\right)\right]^{2}\right]^{1 / 2}}
$$

$R_{m}\left(\lambda_{j}\right)$ was the original value of the reflectance spectra of 10 leaves of jati belanda, which was obtained from measurements with a USB 2000 spectrophotometer. $R_{r}\left(\lambda_{j}\right)$ was a reconstructed spectral reflectance value of 10 leaves of jati belanda, which was obtained through the Wiener estimation technique. The optimal polynomial models to estimate the spectrum was chosen by looking at the average value of RMSE and the value of GFC. The image sample of the test data (the second group), 30 leaves of jati belanda, could be reconstructed into a matrix Yo as reconstructed spectral samples, after the matrix $W$ from the Wiener estimation technique and the model of the best polynomial were obtained.

\section{Evaluating the Data}

Prior to the data evaluation using chemometrics methods, the data was tabulated as in Table 2. The data consisted of 90 reconstructed spectra from three different quality levels of jati belanda samples. The data was subjected to PCA and PLSDA evaluation. For PLSDA, the quality levels of the samples were represented by the dummy variables of $y(y 1, y 2, y 3) . Y 1, y 2$, and $y 3$ represented the $1^{\text {st }}$ month, $2^{\text {nd }}$ month, and $3^{\text {rd }}$ month samples, respectively. The evaluation was carried out using The Unscrambler 10.2 software.

\section{The determination of total flavonoid as quality indicator (BPOM 2004)}

Total flavonoid content in jati belanda samples was determined through several steps of extraction and spectrophotometer measurement. $10 \mathrm{~g}$ of dried powder leaf was macerated using 95\% ethanol for 24 hours. The ethanol solvent from the macerate was evaporated using a rotary evaporator, giving dried crude extract. The dried extract was subjected to a hydrolysis process using hexamethylenetetramine, acetone and $\mathrm{HCl}$ in a reflux system. Then, hydrolysate from the reflux was extracted by solvent-solvent extraction with ethyl acetate. The ethyl acetate extract was treated with $\mathrm{AlCl}_{3}$ to give a colored solution. The flavonoid in the final solution was measured using a UV Vis Spectrophotometer at 425 $\mathrm{nm}$. Finally, its concentration was compared to the calibration of an external standard and presented as $\%$ quercetin.

\section{Results and Discussion}

\section{Analysis of Total Flavonoids from the Chemical Evaluation of the jati belanda Quality}

The analysis of total flavonoids in jati belanda leaves at the ages of 1,2 , and 3 months, using a UVVis spectrophotometer method, was conducted to determine the differences in the concentration of total flavonoids, as well as the quality of sample groups. According to the Ministry of Health (2008), flavonoid compounds can serve as chemical marker of Jati belanda.

Figure 1 shows the mean concentration (\% w / w) of the total flavonoids from Jati belanda leaves from three replicates. The $1^{\text {st }}$ month Jati belanda leaves showed the lowest levels of flavonoid with an average value of $0.67 \%$. The $2^{\text {nd }}$ month was $1.52 \%$, and the highest was from the $3^{\text {rd }}$ month, i.e $2.52 \%$. This data indicated that with the increasing age of a plant, the content of secondary metabolites improved. According to BPOM (2004), the total

Tabel 2. Tabulated data for PCA and PLSDA evaluation

\begin{tabular}{|c|c|c|c|c|c|c|c|c|}
\hline Class & Replicates & $\lambda_{1}$ & $\lambda_{2}$ & $\lambda_{3}$ & $\lambda_{n}$ & $Y_{1}$ & $Y_{2}$ & $Y_{3}$ \\
\hline $1^{\text {st }}$ month & 1.. & \multirow{2}{*}{\multicolumn{4}{|c|}{ Reflectance value of reconstructed spectra }} & 1 & 0 & 0 \\
\hline & 30 & & & & & 1 & 0 & 0 \\
\hline $2^{\text {nd }}$ month & $1 .$. & \multirow{2}{*}{\multicolumn{4}{|c|}{ Reflectance value of reconstructed spectra }} & 0 & 1 & 0 \\
\hline & 30 & & & & & 0 & 1 & 0 \\
\hline \multirow[t]{2}{*}{$3^{\text {rd }}$ month } & $1 \ldots$ & \multirow{2}{*}{\multicolumn{4}{|c|}{ Reflectance value of reconstructed spectra }} & 0 & 0 & 1 \\
\hline & 30 & & & & & 0 & 0 & 1 \\
\hline
\end{tabular}


flavonoid content of jati belanda leaves should not be less than $3.2 \%$, calculated as quercetin. The $3^{\text {rd }}$ month of jati belanda leaves had \% $\mathrm{w} / \mathrm{w}$ close to the value $3.2 \%$, so it is supposed that the jati belanda leaves are best harvested at 3 months, because their chemical quality was better than the chemical content of jati belanda leaves from the $1^{\text {st }}$ and $2^{\text {nd }}$ months.

\section{Reconstruction of Reflectance Spectra from Images of Jati belanda Leaves}

Reconstructing reflectance spectra from an image can be done by using Wiener estimation techniques, $Y_{0}=X$. $W$. The matrix $W$ resulted from mapping between the matrix $X$ and the matrix Yo. Matrix $X$ is a matrix containing the RGB values of the images of 97 standard colors plates and 23 types of leaves of medicinal plants (two leaves for each medicinal plant, total $=46$ ). Matrix $Y_{0}$ is a matrix containing the reflectance value of 97 standard color plates and 46 leaves of medicinal plants. These were measured using an Ocean Optics UV-Vis spectrophotometer USB 2000.

Matrix $X$ and Yo had dimensions $3 \times 143$ and $515 \times 143$, respectively. Utilizing both matrices through transformation with a predetermined polynomial

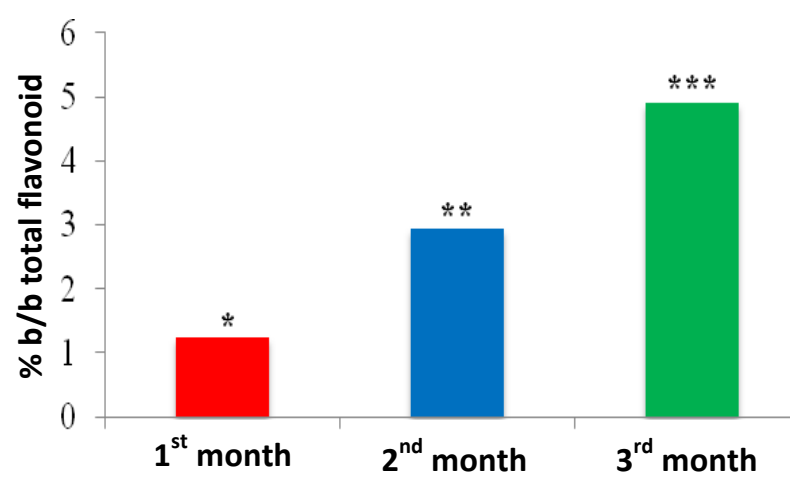

Figure 1. Levels of total flavonoid from Jati belanda leaves. * sign was significantly different at $\alpha=0.05$

model resulted in a matrix $W$ with size $515 \times 3$. Furthermore, matrix $W$ was used to convert the image of the test data to spectral reflectance, matrix Yr. Matrix $\mathrm{Yr}$ was a matrix with spectral reflectance values reconstructed from images of jati belanda leaves. Results from a comparison between the values of matrix Yo and Yr from 10 samples of jati belanda, represented as GFC and RMSE can be seen in Table 3 and Table 4 . Table 3 shows the values of GFC and RMSE from a comparison where $\mathrm{Yr}$ was constructed from $W$ calculated from 97 standard color plates. Table 4 shows the values of GFC and RMSE from a comparison where $\mathrm{Yr}$ was constructed from $W$ calculated from 97 standard color plates and 46 medicinal plant leaves.

Table 3. The value of GFC and RMSE from a comparison where $\mathrm{Yr}$ was constructed from W, calculated from 97 standard color plates

\begin{tabular}{crrrrrr}
\hline \multirow{2}{*}{ Object } & \multicolumn{3}{c}{ RMSE (\%) } & \multicolumn{3}{c}{ GFC } \\
\cline { 2 - 7 } & $\begin{array}{c}\text { Orde 1 } \\
\text { (term 3) }\end{array}$ & $\begin{array}{c}\text { Orde 2 } \\
\text { (term 7) }\end{array}$ & $\begin{array}{c}\text { Orde 3 } \\
\text { (term 10) }\end{array}$ & Orde 1 (term3) & Orde 2 (term 7) & Orde 3 (term 10) \\
\hline Jati belanda 1 & 65.99 & 94.48 & 137.32 & 0.8704 & 0.8929 & 0.8973 \\
Jati belanda 2 & 66.14 & 99.44 & 129.53 & 0.8540 & 0.8803 & 0.8818 \\
Jati belanda 3 & 49.89 & 78.81 & 119.04 & 0.8508 & 0.8805 & 0.8833 \\
Jati belanda 4 & 65.00 & 98.13 & 127.69 & 0.8534 & 0.8824 & 0.8841 \\
Jati belanda 5 & 64.75 & 98.68 & 126.32 & 0.8536 & 0.8825 & 0.8827 \\
Jati belanda 6 & 55.38 & 86.38 & 123.47 & 0.8509 & 0.8803 & 0.8808 \\
Jati belanda 7 & 67.76 & 101.32 & 131.15 & 0.8505 & 0.8797 & 0.8807 \\
Jati belanda 8 & 68.45 & 103.33 & 130.12 & 0.8533 & 0.8808 & 0.8833 \\
Jati belanda 9 & 47.12 & 75.09 & 115.86 & 0.8588 & 0.8852 & 0.8865 \\
Jati belanda 10 & 73.76 & 109.20 & 138.45 & 0.8529 & 0.8779 & 0.8812 \\
\hline Average & 62.42 & 94.48 & 127.90 & 0.8549 & 0.8822 & 0.8842 \\
\hline
\end{tabular}


Table 4. The values of GFC and RMSE from a comparison where $\mathrm{Yr}$ was constructed from $\mathrm{W}$, calculated from 97 standard color plates and 46 medicinal plants leaves.

\begin{tabular}{|c|c|c|c|c|c|c|}
\hline \multirow[b]{2}{*}{ Object } & \multicolumn{3}{|c|}{ RMSE (\%) } & \multicolumn{3}{|c|}{ GFC } \\
\hline & Orde $1^{\text {st }}$ term 3 ) & $\begin{array}{l}\text { Orde 2 } \\
\text { (term 7) }\end{array}$ & $\begin{array}{c}\text { Orde } 3^{\text {rd }} \text { (term } \\
10)\end{array}$ & $\begin{array}{c}\text { Orde } 1^{\text {st }} \text { (term } \\
\text { 3) }\end{array}$ & $\begin{array}{l}\begin{array}{l}\text { Orde 2 } \\
\text { (term } 7 \text { ) }\end{array} \\
\end{array}$ & $\begin{array}{c}\text { Orde } 3^{\text {rd }} \text { (term } \\
10)\end{array}$ \\
\hline Jati belanda 1 & 50.56 & 30.30 & 28.66 & 0.8988 & 0.9696 & 0.9783 \\
\hline Jati belanda 2 & 51.64 & 42.64 & 39.55 & 0.8844 & 0.9510 & 0.9600 \\
\hline Jati belanda 3 & 38.87 & 23.74 & 24.00 & 0.8809 & 0.9509 & 0.9611 \\
\hline Jati belanda 4 & 50.15 & 41.10 & 37.81 & 0.8838 & 0.9517 & 0.9613 \\
\hline Jati belanda 5 & 50.17 & 43.29 & 40.02 & 0.8840 & 0.9514 & 0.9602 \\
\hline Jati belanda 6 & 43.13 & 29.69 & 28.59 & 0.8813 & 0.9511 & 0.9599 \\
\hline Jati belanda 7 & 53.26 & 45.10 & 42.12 & 0.8808 & 0.9485 & 0.9571 \\
\hline Jati belanda 8 & 54.21 & 49.11 & 45.83 & 0.8824 & 0.9428 & 0.9513 \\
\hline Jati belanda 9 & 37.49 & 24.44 & 25.55 & 0.8869 & 0.9441 & 0.9522 \\
\hline Jati belanda 10 & 60.89 & 56.65 & 54.34 & 0.8787 & 0.9274 & 0.9346 \\
\hline Average & 49.04 & 38.60 & 36.65 & 0.8842 & 0.9488 & 0.9576 \\
\hline
\end{tabular}

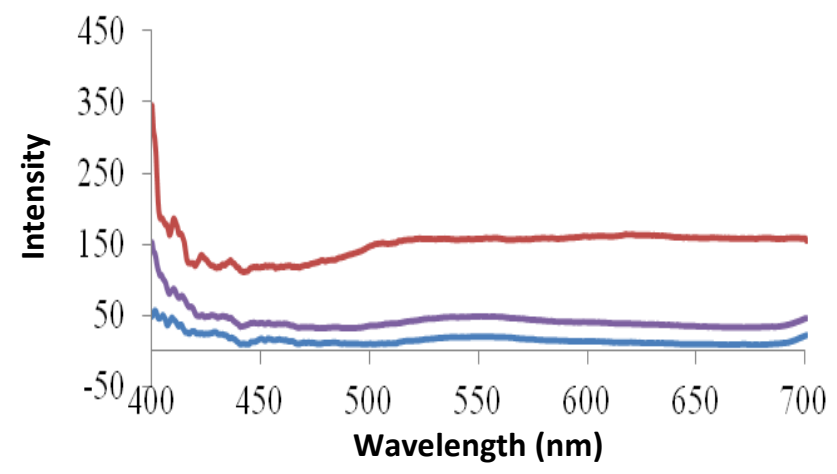

Figure 2 Reflectance spectra for Jati belanda leaves: from reference (blue line), reconstructed spectrum with $\mathrm{W}$ from 97 standard colors plates (red line) and reconstructed spectrum with W from 97 standard colors plates and 46 medicinal plants leaves with 3rd order polynomial (purple line).

Comparing the value of RMSE from Table 3 and Table 4, it was found out that the least RMSE came from the reconstructed spectra calculated using $W$ from 97 standard colors plates and 46 medicinal plants leaves with a 3rd order polynomial (term 10, Table 4). In agreement with that, the highest value of GFC also came from the reconstructed spectra calculated using the same $W$. The goodness of fit coefficient (GFC) was used to test the accuracy of the reconstructed spectra compared to the reference (Nishidate et al. 2013). It seems that the spectral reconstruction process resulted in a satisfactory level of accuracy. The category of spectra reconstruction was excellent if GFC $>=0.9999$, very good when GFC $>=0.999$, good when GFC $>=0.99$, satisfactory if GFC $<0.99$ (Mansouri et al. 2008).

From the above results, the spectral reconstruction process of jati belanda leaves for the remaining discussion used the $W$ matrix from 97 standard color plates and 46 medicinal plant leaves with the 3rd order polynomial. Figure 2 shows a comparison of three spectra coming from the reference measurement, the reconstructed spectrum with W from 97 standard color plates, and W from 97 standard color plates and 46 medicinal plant leaves with the 3rd order polynomial.

\section{Unsupervised Pattern Recognition by PCA}

PCA is an unsupervised pattern recognition technique and it has the ability to summarize multivariate variation. In order to assess the discrimination ability of reconstructed spectra, PCA analysis was employed on the data. By using PCA, a large data set is further reduced to new major variables or principal components (PCs), which can represent the structure and variation in the data (Miller \& Miller, 2000). The PCA analysis was carried out on the original reconstructed spectra of jati belanda leaves, and also on the spectra with 
preprocessing, namely baselining, normalization, and derivatization. The PCA analysis result is described in Figure 3. Both $P C$ score plots showed that the first and the second PCs explained $98 \%$ of the total variability in the original data. Hence, the first two PCs reduce the multivariate data into two dimensional datasets, in which the samples are clustered. The score plot of these first two principal components showed a clear differentiation of the samples based on their chemical composition. The score points of the samples were scattered to become three groups which were marked as group $1^{\text {st }}, 2^{\text {nd }}$, and $3^{\text {rd }}$ month, according to the harvesting time of the jati belanda.

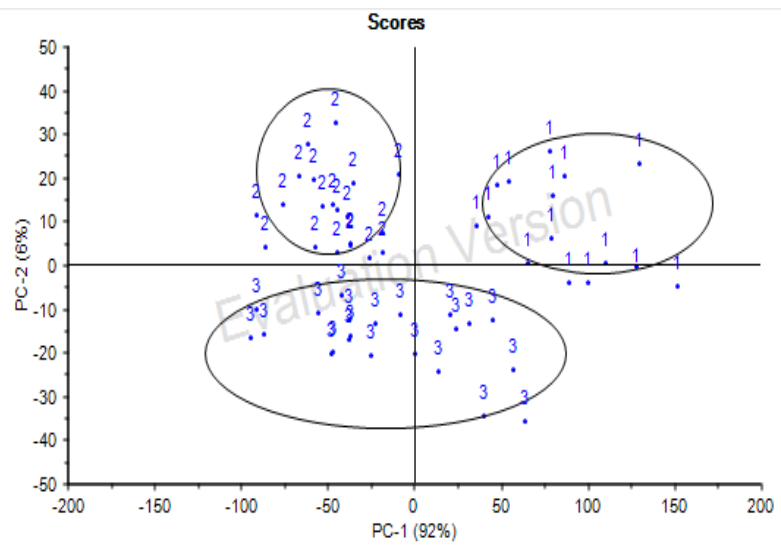

(a)

\section{Quality Prediction Model by PLSDA}

For identification of the quality of unknown samples, a prediction model of the data was generated using PLSDA. PLSDA is a supervised recognition technique, which is used for the classification of objects into a priori given classes. Furthermore, PLSDA is a regression extension of PCA which develops calibration models from two data matrices. Matrix $\mathrm{X}$ is the predictor matrix that contains the original data derived from sample measurements, and matrix $Y$ is the response matrix which is usually consist of dummy variables from the class of the objects ( 1 represents "belongs to the class" and 0 represents "not"). Then, PLSDA calculates scores for the $X$ and $Y$ matrices and utilizes them to create regression models between these values (Lucio-Gutiérrez, Coello, \& Maspoch, 2010).

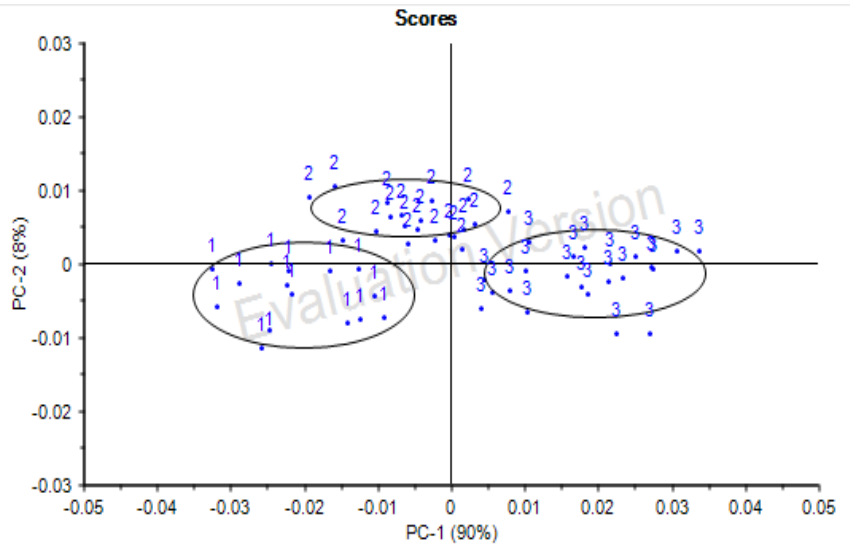

(b)

Figure 3. Plot score of the first two principal components, a) from original reconstructed spectra; b) from spectra with preprocessing

Table 5. Statistical performance of the PLSDA model

\begin{tabular}{cccccc}
\hline \multirow{2}{*}{ Sampel Quality } & Spectral data & \multicolumn{2}{c}{ Calibration } & \multicolumn{2}{c}{ Validation } \\
& & $\mathbf{R}^{2}$ & $\mathbf{R M S E C}$ & $\mathbf{R}^{2}$ & $\mathbf{R M S E P}$ \\
\hline 1 & & 0.8895 & 0.1464 & 0.8490 & 0.1800 \\
2 & Original Data & 0.7783 & 0.2247 & 0.7030 & 0.2676 \\
3 & & 0.8299 & 0.2008 & 0.7876 & 0.2308 \\
\hline 1 & & 0.7753 & 0.2087 & 0.7524 & 0.2245 \\
3 & Data with pre-processing & 0.7226 & 0.2513 & 0.6907 & 0.2723 \\
\hline
\end{tabular}


Table 6. Percentage of accuracy between the reference value and the value of each sample were predicted by PLSDA models from original spectral data.

\begin{tabular}{|c|c|c|c|c|c|c|c|c|c|c|c|c|c|c|c|c|c|c|c|c|}
\hline \multicolumn{2}{|c|}{ Sample } & 1 & 1 & 1 & 1 & 1 & 1 & 2 & 2 & 2 & 2 & 2 & 2 & 3 & 3 & 3 & 3 & 3 & 3 & \\
\hline \multirow{2}{*}{$1^{\text {st }}$ month } & Reference value & 1 & 1 & 1 & 1 & 1 & 1 & 0 & 0 & 0 & 0 & 0 & 0 & 0 & 0 & 0 & 0 & 0 & 0 & Accuracy (\%) \\
\hline & Prediction value & V & V & $\sqrt{ }$ & $x$ & $x$ & $\mathrm{X}$ & V & $\sqrt{ }$ & $\sqrt{ }$ & $\sqrt{ }$ & $\sqrt{ }$ & $\sqrt{ }$ & $\sqrt{ }$ & $\sqrt{ }$ & $\sqrt{ }$ & $\sqrt{ }$ & $\sqrt{ }$ & $\sqrt{ }$ & 83.33 \\
\hline \multirow{2}{*}{$2^{\text {nd }}$ month } & Reference value & 0 & 0 & 0 & 0 & 0 & 0 & 1 & 1 & 1 & 1 & 1 & 1 & 1 & 0 & 0 & 0 & 0 & 0 & Accuracy (\%) \\
\hline & Prediction value & V & V & V & $x$ & $x$ & $x$ & V & $\sqrt{ }$ & V & V & $\sqrt{ }$ & $\sqrt{ }$ & $\sqrt{ }$ & 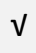 & $\checkmark$ & $v$ & $\sqrt{ }$ & $\sqrt{ }$ & 83.33 \\
\hline \multirow{2}{*}{$3^{\text {rd }}$ month } & Reference value & 0 & 0 & 0 & 0 & 0 & 0 & 0 & 0 & 0 & 0 & 0 & 0 & 1 & 1 & 1 & 1 & 1 & 1 & Accuracy (\%) \\
\hline & Prediction value & V & V & V & V & V & V & $\sqrt{ }$ & $\sqrt{ }$ & $\sqrt{ }$ & $\sqrt{ }$ & $\sqrt{ }$ & $x$ & $\sqrt{ }$ & $\sqrt{ }$ & $\sqrt{ }$ & $\sqrt{ }$ & $\sqrt{ }$ & $\sqrt{ }$ & 94.44 \\
\hline
\end{tabular}

In this analysis, the whole data set was divided into two groups: the calibration and testing sets. The calibration set was used for develop a prediction model, while the testing set was used for the evaluation of the prediction model performance. From the total of 108 datasets available, 90 datasets were used in calibration ( 30 from each sample: $1^{\text {st }}$ month, $2^{\text {nd }}$ month, and $3^{\text {rd }}$ month) and 18 datasets were used for model validation ( 6 from each sample: $1^{\text {st }}$ month, $2^{\text {nd }}$ month, and $3^{\text {rd }}$ month). Thus PLSDA generated 3 calibration models from the samples. Table 5 shows the PLSDA statistical performance for each model. Parameters related to the criteria of goodness of fit of these models are $R^{2}$, root mean square error of calibration (RMSEC), and root mean square error of prediction (RMSEP). All the models gave similar correlation coefficients of around 0.8 , with the error less than 5\%. From the performance values, it seems that the calibration model from the original spectral data gave a slightly better performance compared to the preprocessed spectral data. The validation results of quality prediction model for jati belanda samples are shown in Table 6 . It showed that not all sample data testing can be predicted to have values near 1 for each type of sample. It means that the models could not classify all the testing datasets to their sample types with $100 \%$ accuracy.

\section{Conclusion}

The images of jati belanda samples were collected and reconstructed as a reflection spectrum using Wiener estimation. The best estimator of the $\mathrm{W}$ matrix in the Wiener estimation came from the calculation based on 97 standard color plates and 46 medicinal plants leaves with the 3rd order polynomial. It has 0.9576 of goodness-of-fit coefficient and $36.65 \%$ of root-mean-square-error (RMSE), compared with the experimental spectrum. Principal Component Analysis (PCA) was used to classify the jati belanda reconstructed spectrum based on its quality. A score plot of two PCs that represented $98 \%$ of the variance was able to group the JB spectrum. Further analysis using Partial Least Squares-Discriminant Analysis (PLSDA) showed that the method can result in around $90 \%$ success rate for prediction with external validation.

\section{Acknowledgement}

This research was carried out with the aid of a research grant from Ministry of National Education RI.

\section{References}

Anuradha, V. E. Jaleel, C. A., Salem, M. A., Gomathinayagam, M., \& Panneerselvam, R. (2010). Plant growth regulators induced changes in antioxidant potential and andrographolide content in Andrographis paniculata Wall.ex Nees. Pesticide Biochemistry and Physiology 98, 312-316.

[BPOM] Badan Pengawas Obat dan Makanan RI. (2004). Ekstrak Tumbuhan Obat Indonesia vol. 1. Jakarta: Direktorat Jenderal Pengawasan Obat dan Makanan. 
Borges CN, Bruns RE, Almeida AA, Scarminio LS. 2007. Mixture-mixture design for the fingerprint optimization of chromatographic mobile phases and extraction solutions for Camellia sinensis. Analytica Chimica Acta. 595:28-37.

[Depkes] Departemen Kesehatan. (2008). Farmakope Herbal Indonesia. Edisi 1. Jakarta: Depkes

Febrandy D. 2006. Karakterisasi sifat-sifat tanah dan lahan untuk kesesuaian lahan tanaman Jati Belanda (Guazumaulmifolia Lamk.). [skripsi]. Bogor: Institut Pertanian Bogor.

Gowen AA, O'Donnell CP, Cullen PJ, Bell SEJ. 2008. Recent applications of chemical Imaging to pharmaceutical process monitoring and quality control. European Journal of Pharmaceutics and Biopharmaceutics. 69:10-22.

Kurniawan MF. 2012. Kendali mutu daun Jati Belanda (Guazuma ulmiflia Lamk.) menggunakan Fotometer Jinjing dan teknik pengenalan pola [skripsi]. Bogor: Institut Pertanian Bogor.

Lucio-Gutiérrez JR, Coello J, Maspoch S. 2011. Application of near infrared spectral fingerprinting and pattern recognition techniques for fast identification of Eleutherococcus senticosus. Food Research Internationa. 44:557-565.
Mansouri A, Sliwa T, Hardeberg JY, Voisin Y. 2008. An adaptive-PCA algorithm for reflectance estimation from color images. 19th Internatinal Conference on Pattern Recognition, ICPR 2008, 1-4. New York, NY: IEEE

Miller JC, Miller JN. 2000. Statistics and Chemometrics for Analytical Chemistry. Ed ke4. Harlow (UK): Pearson Education.

Nishidate I, Maeda T, Niizeki K, Aizu Y. 2013. Estimation of melanin and hemoglobin using spectral reflectance images reconstructed from a digital RGB image by the wiener estimation method. Sensors. 13:7902-7915

Orava J, Parkkinen J, Hauta-Kasari M, Hyvönen P, Von Wright A. 2012. Temporal clustering of minced meat by RGB- and spectral imaging. Journal of Food Engineering. 112: 112-116.

Shatilova Y. 2008. Color image technique in fish research [thesis]. Joensuu (FinlaND) : University of Joensuu.

Singh SK, Jha SK, Chaudhary A, Yadava RDS, Rai SB. 2010. Quality control of herbal medicines by using spectroscopic techniques and multivariate statistical analysis. Pharmaceutical Biology. 48:134-141. 